Bulletin UASVM Food Science and Technology 70(1)/2013, 62-63

ISSN-L 2344-2344; Print ISSN 2344-2344; Electronic ISSN 2344-5300

\title{
Research Regarding High Gravity Brewing in the Brewery Pilot Station USAMV Cluj- Napoca
}

\section{Andrei BORŞA, Elena MUDURA*, Vlad Vasile HĂDĂREAN MUNTEANU, Sevastița MUSTE, Andruța CERBU (MUREŞAN), Romina VLAIC}

Faculty of Food Science and Tehnology, University of Agricultural Sciences and Veterinary Medicine

Cluj-Napoca, 3-5 Mănăştur Street, 400372, Cluj-Napoca, Romania

"elena.mudura@usamvcluj.ro

\begin{abstract}
This paper present preliminary research regarding implementation of high gravity beer fermentation process. Production trials were performed in brewery pilot plant from University of Agricultural Sciences and Veterinary Medicine, Faculty of Food Science and Technology. The technological parameters were adapted and monitored during the fermentation process. For high gravity brewing it was use a higher temperature for fermentation at $12^{\circ} \mathrm{C}$. The wort concentration it was set at $18^{\circ} \mathrm{P}$ for a beer with $8 \%$ vol alcohol.
\end{abstract}

Keywords: high gravity brewing, beer, pilot plant

Introduction: High density or high gravity brewing (density greater than $1.070 \mathrm{~kg} / \mathrm{m}^{3}$ ) is a modern procedure that uses for beer production sweet wort with a higher concentration of sugars $\left(18^{\circ}\right.$ Plato) than normal $\left(11-12^{\circ}\right.$ Plato). Therefore it requires a later stage dilution with water, which may occur before or after fermentation to the desired extract and alcohol content. It permits a larger volume of beer to be produced in a brewery compared to full-wort boiling.

Aims: The aims of this paper is to develop and implement a fermentation regime in order to obtain a high gravity beer using the equipment from the brewery pilot plant owned by the Faculty of Food Science and Technology, from USAMV Cluj-Napoca.

Materials and methods: Production trials were performed in brewery pilot plant from USAMV Cluj-Napoca to obtain high gravity beer. The technological parameters were adapted and monitored during the mashing process.

High gravity beer is a filtered beer from concentrated wort. The term "gravity" refers to the amount of dissolved sugar in the wort. Getting this, beer recipe involves changing the parameters and the introduction of additional steps to conventional technology. Thus, after the secondary fermentation and filtration, the beer is diluted with carbonated water to obtain a lower percentage of alcohol, and also to decrease EBC color units, IBU bitterness units and primary extract.

The most important steps in high gravity production are: mashing and fermentation. Whole mash from malt it was used for mashing and infusion regime it was adapted. The original extract of boiled wort it was adjusted at $18^{\circ} \mathrm{P}$.

The fermentation regime took into account the high amount of sugars, so it was use a diagram at $12^{\circ} \mathrm{C}$.

The beer quality parameters were measured during the entire fermentation process according to international standards from Analytica EBC: alcohol by vol. (EBC 9.2), real extract (EBC 9.4), colour (EBC 9.6), bitter units (EBC 9.8) and original extract (EBC 9.4). The final 
product - high gravity beer was filtered and subjected to physical-chemical analysis. The influence of the fermentation parameters on beer quality were analyzed for the purpose of process optimization.

Results: During fermentation were observed decreases in the degree of fermentation, flavour profile changes and yeast viability loss due to stress factors (oxidative, osmotic, heat). The fermentation process can be improved by adding a yeast strain resistant high density, and as the fermentation progresses, adding a different yeast strains with resistance to high concentrations of alcohol.

High gravity technology is suitable for low capacity brewery with insufficient storage capacity, to meet increasing production requirements or seasonal. Brewery design does not require a large production area; energy consumption required for heating, cooling, pumping are reduced proportionately; the final filtering may be carried out at lower temperatures; getting a variety of beers with different alcohol concentrations; use containers of less capacity.

Conclusion: High gravity beer using the equipment from the brewery pilot plant was obtained. The making process is more complex than the traditional technology, due to various parameters (degree of fermentation, flavour, foaming, yeast vitality). This must be taken into account when adding unmalted cereals, nutritional supplements, a larger amount of yeast, and optimal management of a technological process.

\section{REFERENCES}

1. Saerens SM, Verbelen PJ, Vanbeneden N, Thevelein JM, Delvaux FR. 2008. Monitoring the influence of high-gravity brewing and fermentation temperature on flavour formation by analysis of gene expression levels in brewing yeast. Appl Microbiol Biotechnol. 80(6):1039-51

2. Lei, H., Zhao, H., Yu, Z., Zhao, M. 2012. Effects of wort gravity and nitrogen level on fermentation performance of brewer's yeast and the formation of flavor volatiles. Appl Biochem Biotechnol. 166(6):1562-74. 